Feng Z., Boyle P., van Ham M. \& Raab G (2013) Neighbourhood ethnic mix and the formation of mixed-ethnic unions in Britain: a longitudinal analysis Geografiska Annaler: Series B, Human Geography 95(4), 307-321.

http://dx.doi.org/10.1111/geob.12027

\title{
Neighbourhood ethnic mix and the formation of mixed-ethnic unions in Britain: a longitudinal analysis
}

\author{
Zhiqiang Feng (Corresponding author) \\ Longitudinal Studies Centre - Scotland (LSCS) \& School of Geography \& Geosciences, \\ University of St Andrews, St Andrews KY16 9AL, UK, Email: zhiqiang.feng@ st-andrews.ac.uk
}

\section{Paul Boyle}

Longitudinal Studies Centre - Scotland (LSCS) \& School of Geography \& Geosciences, University of St Andrews, St Andrews KY16 9AL, UK, Email: p.boyle@ st-andrews.ac.uk

\section{Maarten van Ham}

OTB Research Institute for the Built Environment, Delft University of Technology, P.O. Box 5030, 2600 GA Delft, The Netherlands, Email: m.vanham @tudelft.nl \& University of St Andrews

\section{Gillian M Raab}

Longitudinal Studies Centre - Scotland (LSCS) \& School of Geography \& Geosciences, University of St Andrews, St Andrews KY16 9AL, UK, Email: g.raab@st-andrews.ac.uk

\begin{abstract}
Although developed societies are becoming increasingly ethnically diverse, relatively little research has been conducted on geographies of mixed-ethnic unions (married or cohabiting). There is some recent evidence from the US that mixed-ethnic couples are more likely to be found in mixed-ethnic neighbourhoods, but this research is based on cross-sectional data. Therefore it is not possible to determine whether mixed-ethnic couples are more likely to form in mixed-ethnic neighbourhoods or whether they are more likely to move there. Our longitudinal analysis allows us to tease out the relative importance of these two processes, furthering our understanding of the formation of mixed-ethnic unions. Using data from the ONS Longitudinal Study (LS) we examine neighbourhood effects on the formation of mixed-ethnic unions in England and Wales. We find that mixed ethnic unions are more likely to form in neighbourhoods with low concentrations of co-ethnic population. The results from this study lend support to the contact theory that geographical proximity to other ethnic groups enhances mutual understanding between people from different ethnic groups and could lead to the development of intimate partnerships.
\end{abstract}

Keywords: mixed-ethnic unions, neighbourhood, ethnic mix, longitudinal analysis, Britain 


\section{Introduction}

Over the past few decades, the number of mixed-ethnic unions has increased substantially, although from a very small base (Coleman 2004). The 1 per cent census sample from the Office for National Statistics (ONS) Longitudinal Study (LS) reveals that the total number of mixedethnic unions reached 5,139 in 2001 in England and Wales, a 46 per cent increase from 1991 (Feng et al. 2010).

Research on mixed-ethnic unions in the UK is relatively limited. Most existing studies focus on primary patterns and trends in the growth of mixed-ethnic unions using data from, for example, the Census or the Labour Force Surveys (LFS) (e.g. Coleman 1985; Ballard 1996; Berrington 1996; Dale and Holdsworth 1997; Coleman 2004; Muttarak 2004; DMAG 2005; Johnston et al. 2006; Voas 2009). The General Household Survey (GHS) has also been used to investigate the extent to which people from ethnic minorities in form mixed-ethnic unions (Muttarak and Heath 2010).

Whether or not people form a mixed-ethnic union does not depend only on individual preferences with respect to socio-demographic characteristics, or the willingness among members of different groups to interact, but also on the opportunities to interact; the opportunity structure of available partners (Blau 1977; Blau et al. 1982; Houston et al. 2005; Niedomysl et al. 2010). Inter-ethnic relations cannot occur unless opportunities for interactions exist. People spend most of their lives in neighbourhoods, schools, workplaces and leisure places, all of which form local marriage markets. Although the use of internet dating site is increasing its effect is still relatively limited (Dutton et al. 2010). The opportunity for inter-ethnic relationships may therefore be influenced by the attributes of local marriage markets, such as the size of the minority group, the availability of potential partners in the minority group, the availability of potential partners in the majority group, and the social and spatial proximity between minority and majority groups (Rosenfeld 2002).

In this study we examine the extent to which the ethnic mix of their neighbourhood settings influences whether people form mixed-ethnic partnerships. Intuitively, we might expect that living in a mixed-ethnic neighbourhood may increase the likelihood of such couple formation, although the literature review suggests that living in neighbourhoods with a low concentration of their own ethnic group is associated with a higher likelihood of out-partnering (Ellis et al. 2006). Particularly, we explore the likelihood that singles from minority ethnic groups choose a White partner in different geographical contexts, and we also explore the likelihood of White singles choosing a non-White partner in different geographical contexts. Our study contributes to theoretical debates regarding two competing hypotheses, contact theory and the social conflict hypothesis, which predict different outcomes regarding the effects of interaction between people from different ethnic groups. This article also contributes to discussions on the role of neighbourhoods in the integration of ethnic minorities in wider society.

It is important to note that we use the term ethnicity instead of race in this article. Ethnic groups, or ethnicity, are more commonly used in the British academic literature to focus on the cultural instead of the biological differences between groups (Coleman and Salt 1996; Stillwell and van Ham 2010). We use data from the Office for National Statistics Longitudinal Study (ONS-LS) which allows us to establish whether living in a mixed-ethnic neighbourhood makes it more likely for people to form a mixed-ethnic union. This longitudinal data is based on the UK Census which includes information on self-reported ethnicity. 


\section{Theoretical background}

The choice of partners is the result of preferences with respect to partner attributes and the opportunity structure of potential partners. By and large, people favour partners who resemble themselves in demographic, social, economic and cultural characteristics - so called marital homogamy. Assimilationist theories (Gordon 1964) suggest that immigrants usually show different cultural and socio-economic characteristics from members of the host society and that these can hamper interactions between immigrants and the host group. The process of assimilation starts with acculturation, proceeds through structural assimilation and is regarded as completed when the ethnicity of immigrants is no longer salient to them or to members of the host society. According to this perspective, the more "assimilated" members of minority groups will be more likely to out-partner with members from majority groups. The observation that second and later generation ethnic minorities experience higher rates of mixed-ethnic unions, and the observation that many mixed-ethnic unions involve ethnic minorities with higher levels of education or qualifications appear to support such theories (Hwang et al. 1997; Muttarak and Heath 2010).

The classical assimilation perspective was largely based upon observations of Europeanorigin immigrants in the US in the nineteenth century. The theory has been criticized for its neglect of ethnic diversity in assimilation patterns in modern times. Segmented assimilation theory posits that different groups experience either traditional assimilation and upward mobility, downward mobility by unsuccessfully competing in the mainstream economy, or upward economic mobility while keeping their own cultural identity (Portes and Zhou 1993; Portes and Rumbaut 2001). Economic assimilation, and socio-spatial assimilation do not always translate into cultural identity assimilation. In Britain, on average, the Black population shows convergence with the host population, although Blacks are more likely than Whites to have a working-class background and live in the inner city. Among South Asian populations in Britain, Indians have enjoyed better economic success while Pakistani and Bangladeshi people have been economically marginalized. However, most South Asians have kept their own cultural identity and shown low levels of out-partnering with Whites (Coleman 2004; Peach 2005).

Blau and colleagues (Blau 1977; Blau et al. 1982) assert that inter-group relations depend not only on preferences among members of different groups to interact, but also on the opportunities to do so. Although assimilation or integration may enhance the willingness to interact, inter-ethnic relations cannot occur unless opportunities for interactions exist. People spend most of their lives in local and functional places such as neighbourhoods, schools, workplaces and leisure places. The opportunity for inter-ethnic relationships is therefore determined by the attributes of local marriage markets such as the size of the minority group, the availability of potential partners in the minority group, the availability of potential partners in the majority group, and the social and spatial proximity between minority and majority groups. Studies have shown that the importance of neighbourhoods or local areas has diminished as a meeting place of potential partners (Bozon and Heran 1989; Houston et al. 2005). However, in our study we deem the place not only as a place for relationship development but more widely as a place of breeding familiarity.

Spatial proximity therefore plays an important role in promoting the probability of intermarriage between ethnic groups (Bossard 1932; Blau 1977; Morgan 1981; Cready and Saenz 
1997). Geographical theories have emphasised the interrelationship between the social and the spatial (Delaney 2002). Places are not simply passive containers reflective of social relations but are influential in constituting and reinforcing social relations (Delaney 2002). Critical geographers have argued that social structure in the host society operates against the inclusion of disadvantaged minorities. Racialization of place could produce circumstances whereby people of certain ethnic group(s) might be excluded from the social process (Delaney 2002; Ellis et al. 2006; Price 2010). On the one hand, ethnic residential segregation reduces opportunities to meet people from different ethnic groups (Peach 1974, 1980). The concentration of a minority group within a neighbourhood also tends to re-enforce the sense of belonging to the group and thus potentially weakens the propensity for exogamy. On the other hand, proximity breeds familiarity, recognition of commonality which potentially leads to the eventual breakdown of ethnicity as a barrier for social interaction (Delaney 2002). As a result, it is expected that the formation of mixed-ethnic partnerships will be affected by these contextual factors (Lievens 1998). Studying the geography of mixed-ethnic unions will shed light on our understanding of processes which influence the integration of ethnic minorities in wider society. Existing literature on segregation focus mainly on the neighbourhood level, while in fact households are more segregated. In addition ethnic mix at the household level cannot be ignored in segregation research because its effects can be substantial (Ellis et al 2012). This study focusses particularly on the role of the neighbourhood context in the formation of mixed-ethnic unions.

While geographers have analysed the importance of spatial proximity to development of inter-ethnic relationships, contact theory hypothesise that contact between ethnic groups is influential in promoting familiarity and may help to breakdown prejudice (Ihlanfeldt and Scafidi 2002). Ellison and Powers (1994) found that inter-ethnic contact, especially if it occurs early in life, increases the likelihood that African Americans and Whites will have close inter-ethnic friendships as adults. Sigelman et al. (1996) confirmed these results in a study in Detroit, showing that early inter-ethnic contact in schools was particularly correlated with more cross ethnic contact as adults. Emerson et al. (2002) also support the role of early interracial contact, relating it to more racially diverse social and friendship circles later in life, including a raised likelihood of attendance at multiracial religious congregations and interracial marriages.

According to social conflict theory, contact between different ethnic groups may also lead to hostility and discrimination (Wessel 2009; Forrest and Dunn 2011; Matejskova and Leitner 2011). Matejskova and Leitner (2011) in their study on Russian immigrants in eastern Berlin found that contact between local natives and Russian immigrants only re-enforced pre-existing stereotypes, prejudices and conflicts. Forrest and Dunn (2011) show that although people in more diverse places favour multiculturalism, older and less educated people are more likely to oppose immigration when confronted with others. Tolsma et al. (2007) found that proximity of ethnic out-group members in the municipality reduces opposition to exogamy. At the neighbourhood level the same effect only appears for the more educated while proximity of ethnic out-groups increases opposition to ethnic intermarriage for less educated. Matejskova and Leitner (2011) argue that geographers have paid little attention to the contact hypothesis or social conflict theory literature. We intend to fill this gap by investigating whether spatial proximity to people outside one's own group is associated with the likelihood of forming a mixed ethnic union. The contact hypothesis and social conflict theory predict different outcomes and our study can provide evidence on which theory is supported in understanding inter-ethnic relationship formation in the British context. 
More recently, Holloway et al. (2005) investigated the factors which increased the likelihood of mixed-ethnicity households living in predominantly White neighbourhoods in the US. They found that mixed-ethnic households were more likely to live in mixed neighbourhoods than single ethnic households. However, because this research was based on cross-sectional data it is impossible to identify whether mixed-ethnic couples were more likely to form in mixedethnic neighbourhoods, or whether selective mobility occurred as these couples sought out mixed residential neighbourhoods. To explore these issues in detail requires longitudinal data.

\section{Data and methods}

The Office for National Statistics Longitudinal Study (ONS-LS) is a nationally representative 1per cent sample of the English and Welsh population based on 4 birthdates, providing a sample of about 500,000 people. The data includes information from the 1971, 1981, 1991 and 2001 Censuses as well as vital events registrations of births, deaths, immigrations, embarkations and re-entries. However, registrations of marriage or divorce are not linked. An LS member who married sometime between 1991 and 2001, and then divorced before 2001 would be omitted in the analysis. The study was designed as a continuous, multi-cohort study with samples drawn from successive censuses using the same selection criteria. Data are also collected for people in the same household as members of ONS-LS, but the records for these individuals are not linked through time. Apart from the individual-level micro data, the ONS-LS includes a number of variables from the censuses which describe the characteristics of the small areas in which each sample member lived. As the individual data is geocoded, it is possible to attach extra small area variables, such as the ethnic composition variables developed in this study, to individual ONSLS members (Hattersley and Creeser 1995).

We used data from the 1991 and 2001 Censuses, because questions on ethnicity were first introduced in 1991. However, the ethnicity questions in the 1991 and 2001 Censuses were different. Both the question wording and range of ethnic categories used changed in 2001. For example, unlike in the 1991 census respondents were allowed to report themselves as being Irish or as having a Mixed ethnic origin. Following previous studies (Platt et al. 2005; Bradford 2006) we identified five broad ethnic groups: White, Black, South Asian, Other Asian, and Other (Table 1) which were comparable between 1991 and 2001. However, in our analyses we excluded Other which is a small, heterogeneous group.

\section{[INSERT TABLE 1 ABOUT HERE]}

Between 1991 and 2001 a small proportion of people changed the way they reported their ethnicity. This was most common among the mixed-ethnic and Black groups. In this study, we used the 2001 variable to establish the ethnicity for each LS member as this was the latest category a member reported using the more detailed question available in 2001 . We excluded LS members with imputed ethnicity as this has been shown to be unreliable (Platt et al. 2005).

Opposite-sex couples who were either married or cohabiting and who were from different ethnic groups were defined as being in mixed-ethnic unions (see also Berrington 1996; Liang and Ito 1999; Wong 1999; Model and Fisher 2002; Coleman 2004). We included cohabiting couples as their number has grown dramatically over the last few decades, making them an important 
element of mixed-ethnic unions. In addition, since mixed-ethnic unions are small in number, including cohabiting couples boosts the sample size and improves the statistical power of our models.

Previous studies suggest that the ethnic mix of people's residential context influences the probability of forming mixed-ethnic partnerships. However, the scale at which people's residential contexts should be measured is debateable (van Ham and Feijten 2008; van Ham and Manley 2010). With regard to union formation, people meet potential partners, for example, at school, in the workplace and at leisure places and these can stretch from the direct surroundings of the home to the neighbourhood, to whole cities and larger regions. Together, these meeting places form the local marriage market area. In this study, marriage markets were measured at two spatial levels: local government districts and wards. Local government districts have average populations of around 120,000 (regional marriage market area) while wards have populations of around 6,000 (neighbourhoods or local marriage market area). We calculated the ethnic mix of the population at both spatial scales: ethnic marriage market areas (districts) and neighbourhoods (wards) in England and Wales. This concentration measure is ethnic group specific, based on the proportion of that group in an area. Thus for South Asian people, the concentration was based on the proportion of the South Asian population in districts and wards. For Whites, the measure is based on the proportion of the White population.

Apart from focusing on district and ward-level measurements of ethnic concentration, we also used a combination of the two spatial scales. Someone might live in an ethnically homogeneous ward, but within an ethnically diverse district, or the other way around. To examine the combined effect of district and ward level ethnic concentrations, we therefore included in the model the interaction term of co-ethnic concentration at both district and ward levels.

We used both descriptive methods and multivariate models to investigate the formation of mixed-ethnic unions that involved a minority and a White partner. We estimated the likelihood of out-partnering for singles in 1991 using multinomial logit regression. The dependent variable was the partnership status in 2001: in co-ethnic unions (0), in mixed-ethnic unions (1), and remaining single (2). These models produced two sets of coefficients, separately predicting the propensity of forming a mixed-ethnic union in comparison to forming a co-ethnic union and predicting the propensity of remaining single compared to being in a co-ethnic union. We only present details of the coefficients for the part of which compares mixed-ethnic unions between a minority and a White partner with co-ethnic unions. The predicted percentages of mixed ethnic unions according to ward and district ethnic concentration use both parts of the model. We did not analyse mixed-minority unions as they are very rare.

\section{Formation of mixed-ethnic unions}

\section{Sample descriptions}

The sample used to model the probability of forming a mixed-ethnic union includes single people who were aged 6 and over in 1991 and who were also recorded in the 2001 Census (by then aged 16 and over). The sample comprises a total of 129,917 people: 2,422 Blacks, 4,017 South Asians, 697 Other Asians, and 122,781 Whites (Table 2). By 2001, about 25 per cent of the 1991 singles from three minority groups ended up living with a partner from either the same 
ethnic group or the White group. Single South Asians were the most likely to form a partnership, with almost one third of them having formed a partnership by 2001. In contrast, Black singles were the least likely to enter a partnership with only 18 per cent being married or cohabiting in 2001. Of all those who lived with a partner in 2001, 48 per cent of Blacks, 11 per cent of South Asians, and 42 per cent of Other Asians had chosen a White partner. The proportions are much higher than the overall 2001 prevalence rate of mixed-ethnic unions for ethnic minorities, demonstrating that those who formed a partnership between 1991 and 2001 were more likely to partner with someone from the majority group than those who formed a partnership earlier (Feng et al. 2010). For White LS members 31 per cent of the 1991 singles entered a partnership by 2001. Only 1.7 per cent of the partnerships involving a White individual were mixed-ethnic unions with a non-White individual.

\section{[INSERT TABLE 2 ABOUT HERE]}

The multivariate models include several individual level control variables which are expected to be related to the likelihood of out-partnering: gender, age, country of birth, qualifications, social class, housing tenure, and region. The selection of these variables was based on a literature review (Berrington 1996; Voas 2009). Age is an important factor in affecting partner choice. Young people tend to be more open minded in their choice of partners. However, people gain greater maturity and possible greater exposure to different ethnic populations when growing older (Lievens 1998; Muttarak and Heath 2010). So it is not clear whether the likelihood of out-partnering increases with age. We grouped age in 1991 into three groups: 6-14 years old, 15-24 years old and 25 and over years old. Country of birth was classified into either born in the UK or outside the UK. According to the assimilationist perspective, people who are second and later generation immigrants will be more proficient at the local language and have more exposure to the host culture. In contrast, people born outside the UK are expected to have lower tendencies in forming mixed ethnic unions as their shorter period of exposure to the host culture will cause them to be less integrated into it than their counterparts born in the host country.

Educational qualification has been found to have a positive effect on mixed ethnic unions (Lieberson and Waters 1988; Kalmijn 1998). It is argued that higher education weakens traditional attachment to the ethnic group and being at a higher education institution makes encounters with people from outside one's own group more likely (Muttarak and Heath 2010). We grouped educational qualifications into dichotomous categories: no degree and with degree. We expected people with degrees to have higher probabilities of out-partnering for all ethnic groups, except for Black people as shown in previous British studies (Berrington 1996).

Social class is also an important determinant of partner choice (Kalmijn 1998). Higher socio-economic positions represent success in socioeconomic assimilation. Out-partnering varies by social position with, for example, South Asians in higher social classes more likely involved in partnerships with White people (Berrington 1996). We chose Registrar's Social Class and used five categories: professional \& managerial occupations, skilled non-manual, skilled manual, partly skilled \& unskilled, and not stated. The unstated category covers people who were unemployed, economically inactive, or who did not report occupations and therefore did not have social class assigned. In general we expected people with higher social backgrounds to have 
a higher propensity of out-partnering especially for South Asian and White groups. For LS members who were under 21 and in full-time education, the social class and educational qualifications of the head of household were used as proxies.

Housing tenure reflects living arrangement and possibly the financial situation of the family. We would expect people who lived in owner occupied houses to be more integrated within the host society and therefore were more likely to form mixed ethnic unions. We also included region in the model to account for regional variations in the history of immigration settlement and increasingly spatial widening marriage fields (Niedomysl et al. 2010). Summary statistics for these control variables are given by ethnic group in Table 3.

\section{[INSERT TABLE 3 ABOUT HERE]}

\section{Modelling results}

Table 4 presents the results of four multinomial logistic regression models, one for each ethnic group. For each of the non-White ethnic groups we model the probability that a single person in 1991 forms a mixed-ethnic union with a White person or remains single by 2001, compared to those who form a union with someone from the same ethnic group. For the White group we model the probability that a single person in 1991 forms a mixed-ethnic union with a non-White person or remains single by 2001. Note, again, that for brevity we only present the model parameters for the mixed-ethnic category. For each ethnic group, we fitted regressions including the interaction term between district level and ward level co-ethnic concentration.

\section{[INSERT TABLE 4 ABOUT HERE]}

As expected, those born outside the UK were less likely to live with a White partner by 2001 compared to those born in the UK, for all three ethnic minority groups. For Blacks, the model shows higher rates of out-partnering at younger ages but no significant effect at older ages. No significant effects on out-partnering were found by gender, social class, qualifications or housing tenure for Blacks. For South Asians, the odds of out-partnering increase with age and social class. Since age in the model refers to age in 1991 rather than age at the formation of marriage or cohabitation, its effect here should be better considered as a cohort effect. For Other Asians, women were more likely than men to choose a White partner, a pattern which differs from the Black or South Asians, where we found no gender differences. Other Asians in skilled manual occupations were more likely to partner with a White person than those in other occupations, although note that there was a relatively small number in this group. Housing tenure and qualifications were not found to have an effect on the probability of out-partnering for South Asians and Other Asians. The odds of forming a mixed ethnic union are relatively little affected by region.

For White people, the odds ratios of forming a partnership with a non-White partner were highest for those in the youngest age group (6-14 in 1991), for those with a degree or higher qualifications, and for those in private renting. Living in London also elevated the likelihood of out-partnering with non-White people. 
It is not straightforward to interpret the coefficients of district and ward level concentration of co-ethnic group because of the interaction between the ward and district level coefficients in the models. To aid understanding we have calculated the predicted out-partnering rates as a percentage of the entire cohort at different ward and district percentages of the ethnic groups concerned. These percentages are obtained by a product of the fitted proportion forming any kind of partnership with the fitted proportions of mixed-ethnic partnerships as a proportion of all partnerships. The first of these (data not shown) was much less influenced by the ethnic composition of neighbourhoods than was the second.

The results were plotted (Figure 1-4) for selected percentages of the relevant ethnic groups at ward and district level. The percentages of co-ethnics for which the predicted values were calculated were selected to cover the range of values in the data. Ward and district combinations where the sample size for the relevant ethnic group was less than 10 were excluded from the plots. In the calculations, all control variables were set to their mean value, apart from the percentages of co-ethnics at the district and ward levels. For each ethnic group the highest outpartnering rate was found when both districts and wards have low concentrations of the relevant ethnic group. But the effect of the combined geography differs by ethnic group.

Figure 1 shows that the out-partnering rates with Whites for Blacks decrease with the increase of both district level and ward level proportion of Blacks, when the other level held fixed. However, when either ward or district level of per cent Black is high an increase in the level for the other geography causes little or no further decrease in out partnering. Thus a high concentration of Blacks at either ward or district level leads to low out-partnering rates. The effect of district level concentration and ward level concentration on out-partnering with Whites is almost the same. For example, the out-partnering rate is 8.0 per cent in a ward with 4 per cent of Blacks that is surrounded by a district with 4 per cent of Blacks. This rate fells to 6 per cent if the same level of ward is in a district with 10 per cent of Blacks. In comparison, if the district level of per cent Blacks is 4 and the ward level of per cent Blacks changes from 4 to 10 per cent, the out-partnering rate changes from 8 to 6 per cent, identical to the change in the former circumstance.

\section{[INSERT FIGURE 1 ABOUT HERE]}

For South Asians, the pattern is quite different (Fig. 2). Although both district and ward level of South Asian concentrations are associated with the likelihood of out-partnering with Whites, the ward geography is the more important determinant of the formation of mixed ethnic unions. Out-partnering rates decline with an increase in the percentage of South Asians in the ward for all concentrations of South Asians in the district, while the effect of district at a fixed ward concentration is smaller and inconsistent. For low-concentration wards, out-partnering rates with Whites decrease with district level concentration. In contrast, for wards with a high concentration of South Asians (e.g. $10 \%$ ) out-partnering rates with Whites increase with concentration at the district level. In summary, it is the ward geography that is important for couple formation among South Asians, with the wider area (district) having a very minor effect.

\section{[INSERT FIGURE 2 ABOUT HERE]}


For other Asians the pattern is similar to that for South Asians (Fig. 3). When the proportion of Other Asians at the district level is relatively low the out-partnering rates decrease with the proportion of Other Asians at the ward level. In contrast if the proportion of Other Asians at the district level is relatively high the out-partnering rates decrease only marginally with the proportion of Other Asians at the ward level. The relationship between out-partnering rates and district level concentrations of Other Asians varies with the ward level concentration of Other Asians. If the ward level concentration is low (e.g. under $2 \%$ ) out-partnering rates decrease with the district level concentration. However, once the ward percentage of Other Asians reaches 2 per cent the trend with the district level is reversed, so that higher rates of outpartnering are found in the districts with greater Other Asian concentrations. Examination of the data showed that the wards with high concentrations at both geographies were mainly concentrated in London or in the centres of cities with large student populations. However, we should be careful in interpretation of the result for Other Asians because of the relatively small numbers of events involved.

\section{[INSERT FIGURE 3 ABOUT HERE]}

For Whites the proportion in mixed-ethnic unions with non-Whites decreases from its highest level with an increase in proportion of Whites at both district and ward level (Fig. 4). The effect of district is similar to, although slightly lower than the effect of wards. For example, the proportion of out-partnering with non-Whites decreases from 6.6 per 1000 singles in 1991 to 5.0 per 1000 when the proportion of White population at the ward level increases from 85 to 96 per cent and the district level White concentration is 98 per cent. In comparison, the proportion of out-partnering with non-Whites decreases from 6.5 per 1000 to 5.0 per 1000 when the proportion of White population at the district level increases from 85 to 96 per cent and the ward level White concentration is 98 per cent.

\section{[INSERT FIGURE 4 ABOUT HERE]}

\section{Conclusions}

Mixed-ethnic households have been largely ignored in previous studies of geographical segregation. This is perhaps due to the fact that mixed ethnic households are small in numbers. However, the number of such households is growing, and their growth signals an important breakdown of ethnic barriers within households (Holloway et al 2005; Ellis et al 2012). Studying the geography of mixed-ethnic unions sheds light on the role of neighbourhoods in the integration of ethnic minorities, but also contributes to our understanding of geographies of encounter in general (Matejskova and Leitner, 2011). From the few studies conducted in the US (Iceland and Nelson 2010; Ellis et al. 2007, 2012), it has been discovered that the geography of mixed-ethnic households differs from that of co-ethnic households. For example, mixed-ethnic couples in the US were found to be more likely to live in mixed neighbourhoods than co-ethnic households (Holloway et al. 2005) and this was suggested to relate mainly to residential decision 
making. In fact, mixed-ethnic households may choose to live in mixed neighbourhoods, but they may also be more likely to form there and it is not possible to tease out the relative importance of these different processes using cross-sectional data.

In this study we made use of longitudinal data, which provided an opportunity for us to investigate whether spatial proximity to other ethnic groups influences the propensity of outpartnering. Particularly, we examined whether minority ethnic people who live in less ethnically concentrated areas were more likely to form a partnership with a White person than those in more ethnically concentrated areas. If this is true then the observed pattern by Ellis et al. (2006) could at least partly be attributed to the process of the formation of mixed-ethnic unions, rather than purely attributed to a subsequent migration process. Furthermore, we also examined whether majority White people who live in more ethnically concentrated areas were more likely to form a union with a non-White person than those in less ethnically concentrated areas. An affirmative finding would lend further support to the hypothesis that the formation of mixedethnic union was influenced by geographical proximity to other ethnic groups.

We used data from the ONS-LS, which is a nationally representative sample of the population in England and Wales and estimated the likelihood of out-partnering with a White person for three ethnic minority groups, Black, South Asian, and Other Asian. We also estimated the likelihood of out-partnering with a non-White person for the White group. The likelihoods were estimated in relation to ethnic mix, controlling for individual characteristics. We used both districts and wards to define regional and local marriage market areas and we included an interaction term between districts and wards to explore the relative importance of the two geographical levels within the same modelling framework. This approach allowed us to distinguish between wards with high concentrations of minorities within a White dominant district and similar wards in districts with high concentrations of ethnic minorities.

Districts and wards are both shown to be relevant geographies as people cultivate their social networks, and relationships not only in their immediate neighbourhoods but also in workplaces, schools and local leisure centres. Wards are approximations of immediate neighbourhoods where people interact through daily activities, including going to school and shopping. Districts are better proxies for working or other social networking experiences. The level of concentration of ethnic minorities at both district and ward level were found to have significant effects on the probability of forming mixed-ethnic unions for Blacks, South Asians, Other Asians, and Whites, but their relative importance vary by ethnic group. In general, low concentrations of co-ethnic group are associated with increased out-partnering rates, arguing for the importance of local availability of partners and proximity to outgroup members as determinants of couple formation. For Blacks and Whites, the district and ward of co-ethnic concentrations have same effects. For South Asians and Other Asians the co-ethnic concentration at the ward level was more important than the concentration at the district level, although both were important. One aspect of our findings for Other Asians and South Asians may suggest that other factors may also be playing a part. For both of these groups wards with high concentrations of the ethnic group within high concentration districts had higher rates of co-ethnic unions than would have been predicted from a model that considered the availability of partners as the important determinant. One possible interpretation of these patterns could be that the potential for the breakdown of inter-ethnic barriers is greatest when both the ward and district concentration of an ethnic minority is high, and this could lead to a relative increase in mixed ethnic unions. Research on social interaction between South Asians, Other Asians and Whites is therefore needed to enhance our 
understanding of the factors influencing this. We should also take caution in interpreting the results, particularly for Other Asians, due to the relatively small numbers.

The negative association between the propensity of out-partnering and neighbourhood concentrations of their own ethnic group is in line with a small number of previous studies (Hwang et al. 1994; Hwang et al. 1997; Lievens 1998; Muttarak and Heath 2010), although these were based on measures calculated for much larger geographical areas. Thus, those ethnic minorities living in areas with high concentrations of their own group have a greater chance of meeting potential partners from their own group. Larger concentrations of a minority group may also enforce the identity of the group and discourage exogamous relationships. In contrast, in areas with a low concentration of a particular minority group the opportunities for meeting a partner from their own group is constrained, elevating the probability of developing a relationship with someone from the majority White group.

Although using a large and rich data set, we acknowledge that our research has some limitations. For example we did not have information on migration between 1991 and 2001, nor did we have information on the timing of marriage or cohabitation. Therefore we could not explore whether LS members were more likely to out-partner following a move into a neighbourhood with a lower concentration of their own group. If an individual married or cohabitated sometime between 1991 and 2001, and then separated before 2001 we would have ignored these events. Especially if mixed ethnic unions are more prone to dissolution (Kalmijn et al. 2005; Feng et al 2012), the results here may be biased. Another issue is that we have not been able to tackle the potential endogenous effect that people living in areas with a lower concentration of their own group might have unobserved attributes which made them more likely to form mixed ethnic unions. We could tackle this using an instrumental variable approach (Heckman 1978), but we have not been able to find an appropriate instrument.

A good number of studies of geographical influences on mixed-ethnic unions have used cross sectional data and have usually been based on ecological relationships between outpartnering and segregation measures (Kalmijn 1998). Our study is the first to use longitudinal micro data incorporating individual and geographical variables to explore how neighbourhood ethnic mix influences the propensity of out-partnering. Our study suggests that neighbourhood ethnic mix does influence the formation of mixed ethnic unions, despite the growing recognition that people's social networks clearly span beyond the local geographical area (Kalmijn and Flap 2001). The results from this study lend support to the contact theory that geographical proximity to other ethnic groups enhances mutual understanding between people from different ethnic groups and could lead to development of partnerships (Ihlanfeldt and Scafidi 2002). This article also supports the proposition by Blau (1982) that social structure is influential in affecting the formation of mixed-ethnic unions. With the prospect that ethnic minorities are likely to further disperse into predominantly White areas (Simpson and Nissan 2009) we expect contacts between different ethnic groups may grow and as a consequence mixed ethnic unions will increase and benefit the mutual acceptance of different cultures in Britain. An increase in mixed ethnic unions will require a rethink of the meaning of ethnic segregation in cities, and ways to measure it. As has been noted elsewhere (Ellis et al 2012), and supported by our findings, future geographical studies on ethnic segregation have to take mixing at the household level into account in the future. 


\section{Acknowledgements}

This research is funded by the ESRC under the Understanding Population Trends and Processes (UPTAP) programme (Award Ref: RES-163-25-0045). The permission of the Office for National Statistics to use the Longitudinal Study is gratefully acknowledged, as is the help provided by support officers of the Centre for Longitudinal Study Information \& User Support (CeLSIUS). CeLSIUS is supported by the ESRC Census of Population Programme (Award Ref: RES-348-25-0004). The data from ONS is Crown copyright and reproduced with the permission of the controller of HMSO and Queen's Printer for Scotland. This work uses research datasets which may not exactly reproduce National Statistics aggregates. We also would like to thank reviewers and the editors of Geografiska Annaler: Series B, Human Geography for their important inputs to this article. The authors alone are responsible for the interpretation of the results.

\section{References}

BALLARD, R. (1996): 'Negotiating race and ethnicity: exploring the implications of the 1991 census', Patterns of Prejudice 30 (3): 3-33.

BERRINGTON, A. (1996): 'Marriage patterns and inter-ethnic unions', in COLEMAN, D. and SALT, J. (eds): Ethnicity in the 1991 Census, vol. 1: Demographic Characteristics of the Ethnic Minority Populations. HMSO, London, pp. 178-212.

BLAU, P. M. (1977): Inequality and Heterogeneity: A Primitive Theory of Social Structure. Free Press, New York.

BLAU, P. M., BLUM, T. C. and SCHWARTZ, J. E. (1982): 'Heterogeneity and intermarriage', American Sociological Review 47 (1): 45-62.

BOSSARD, J. H. (1932): 'Residential propinquity as a factor in marriage selection', American Journal of Sociology 38 (2): 219-224.

BOZON, M. and HERAN, F. (1989): 'Finding a spouse: a survey of how French couples meet', Population: An English Selection 44 (1): 91-121.

BRADFORD, B. (2006): 'Who are the "Mixed" ethnic group?', Office for National Statistics, London, May.

COLEMAN, D. (1985): 'Ethnic intermarriage in Great Britain', Population Trends 40: 4-10.

COLEMAN, D. (2004): 'Partner choice and the growth of ethnic minority populations', Bevolking en Gezin 33 (2): 7-34.

COLEMAN, D. and SALT, J. (1996): 'The ethnic group question in the 1991 census: a new landmark in British social statistics', in COLEMAN, D. and SALT, J. (eds): Ethnicity in the 1991 Census, vol. 1: Demographic Characteristics of the Ethnic Minority Populations. HMSO, London, pp. 1-32.

CREADY, C. M. and SAENZ, R. (1997): 'The nonmetro/metro context of racial/ethnic outmarriage: some differences between African Americans and Mexican Americans', Rural Sociology 62 (3): 335-362. 
DALE, A and HOLDSWORTH, C. . (1997): 'Issues in the analysis of ethnicity in the 1991 British Census: evidence from microdata', Ethnic and Racial Studies 20 (1): 160-181

DMAG (2005): 'Inter-ethnic unions'. DMAG Update, Census update 2005/12, Data Management and Analysis Group, Greater London Authority, London, November.

DELANEY, D. (2002): 'The space that race makes', Professional Geographer 54 (1): 6-14.

DUTTON, W. H., HELSPER, E. J., WHITTY, M. T., BUCKWALTER, J. G, and LEE, E. (2010): Mate selection in the networked society: the role of the Internet in reconfiguring marriages in Australia, the United Kingdom and United States. Working paper, Oxford Internet Institute, University of Oxford, 10 November.

ELLIS, M., WRIGHT, R. and PARKS, V. (2006): 'The immigrant household and spatial assimilation: partnership, nativity, and neighborhood location', Urban Geography 27 (1): $1-19$.

ELLIS, M., HOLLOWAY, S. R., WRIGHT, R. and East, M. (2007): 'The effects of mixed-race households on residential segregation', Urban Geography 28 (6): 554-577.

ELLIS, M., HOLLOWAY, S. R, WRIGHT, R. and FOWLER, C. S. (2012): 'Agents of change: mixed-race households and the dynamics of neighborhood segregation in the United States', Annals of the Association of American Geographers 102 (3): 549-570.

ELLISON, C. G. and POWERS, D. A. (1994): 'The contact hypothesis and racial attitudes among black Americans', Social Science Quarterly 75 (2): 385-400.

EMERSON, M. O., KIMBRO, R. T. and YANCEY, G. (2002): 'Contact theory extended: the effects of prior racial contact on current social ties', Social Science Quarterly 83 (3): 745761.

FENG, Z., BOYLE, P., VAN HAM, M. and RAAB, G. (2010): 'Neighbourhood ethnic mix and the formation of mixed-ethnic unions in Britain', in STILLWELL, J. and VAN HAM, M. (eds): Ethnicity and Integration. Understanding Population Trends and Processes 3, Springer, Heidelberg, pp. 83-103.

FENG, Z., BOYLE, P., VAN HAM, M. and RAAB, G. (2012): 'Are mixed ethnic unions more likely to dissolve than co-ethnic unions? New evidence from Britain', European Journal of Population, 28(3): 159-176

FORREST, J. and DUNN, K. (2011): 'Attitudes to diversity: new perspectives on the ethnic geography of Brisbane, Australia', Australian Geographer 42 (4): 435-453.

GORDON, M. M. (1964): Assimilation in American Life: The Role of Race, Religion, and National Origins. Oxford University Press, New York.

HATTERSLEY, L. and CREESER, R. (1995): The longitudinal study, 1971-1991: history, organisation and quality of data. Office of Population Censuses and Surveys, Series LS 7, HMSO, London.

HECKMAN, J. J. (1978): 'Dummy endogenous variables in a simultaneous equation system', Econometrica 46 (4): 931-959. 
HOLLOWAY, S. R., ELLIS, M., WRIGHT, R. and HUDSON, M. (2005): 'Partnering "out" and fitting in: residential segregation and the neighbourhood contexts of mixed-race households', Population, Space and Place 11 (4): 299-324.

HOUSTON, S., WRIGHT, R., ELLIS, M., HOLLOWAY, S. and HUDSON, M. (2005): 'Places of possibility: where mixed-race partners meet?', Progress in Human Geography 29 (6): 700-717.

HWANG, S.-S., SAENZ, R. and AGUIRRE, B. E. (1994): 'Structural and individual determinants of outmarriage among Chinese-, Filipino-, and Japanese-Americans in California', Sociological Inquiry 64 (4): 396-414.

HWANG, S.-S., SAENZ, R. and AGUIRRE, B. E. (1997): 'Structural and assimilationist explanations of Asian American intermarriage', Journal of Marriage and the Family 59 (3): 758-772.

ICELAND, J. and NELSON, K. A. (2010): 'The residential segregation of mixed-nativity married couples', Demography 47 (4): 869-893.

IHLANFELDT, K. R. and SCAFIDI, B. P. (2002): 'The neighbourhood contact hypothesis: evidence from the Multicity Study of Urban Inequality', Urban Studies 39 (4): 619-641.

JOHNSTON, R., POULSEN, M. and FORREST, J. (2006): 'Ethnic residential segregation and assimilation in British towns and cities: a comparison of those claiming single and dual ethnic identities', Migration Letters 3 (1): 11-30.

KALMIJN, M. (1998): 'Intermarriage and homogamy: causes, patterns, trends', Annual Review of Sociology 24: 395-421.

KALMIJN, M. and FLAP, H. (2001): 'Assortative meeting and mating: unintended consequences of organized settings for partner choices', Social Forces 79 (4): 1289-1312.

KALMIJN, M., DE GRAAF, P. M. and JANSSEN, P. G. (2005): 'Intermarriage and the risk of divorce in the Netherlands: the effects of differences in religion and in nationality, 197494', Population Studies 59 (1): 71-85.

LIANG, Z. and ITO, N. (1999): 'Intermarriage of Asian Americans in the New York City region: contemporary patterns and future prospects', International Migration Review 33 (4): 876-900.

LIEVENS, J. (1998): 'Interethnic marriage: bringing in the context through multilevel modelling', European Journal of Population/Revue européenne de Démographie 14 (2): $117-155$.

LIEBERSON, S. and WATERS, M. C. (1988): From Many Strands: Ethnic and Racial Groups in Contemporary America. Russell Sage Foundation, New York.

MATEJSKOVA, T. and LEITNER, H. (2011): 'Urban encounters with difference: the contact hypothesis and immigrant integration projects in eastern Berlin', Social and Cultural Geography 12 (7): 717-741.

MODEL, S. and FISHER, G. (2002): 'Unions between blacks and whites: England and the US compared', Ethnic and Racial Studies 25 (5): 728-754. 
MORGAN, B. S. (1981): 'A contribution to the debate on homogamy, propinquity, and segregation', Journal of Marriage and the Family 43 (4): 909-921.

MUTTARAK, R. (2004): 'Marital assimilation: interethnic marriage in Britain', paper prepared for 12th Biennial Conference of the Australian Population Association, 15-17 September 2004, Canberra, ACT.

MUTTARAK, R. and HEATH, A. (2010): 'Who intermarries in Britain? Explaining ethnic diversity in intermarriage patterns', British Journal of Sociology 61 (2): 275-305.

NIEDOMYSL, T., ÖSTH, J. and VAN HAM, M. (2010): 'Globalisation of marriage fields: the Swedish case', Journal of Ethnic and Migration Studies 36 (7): 1119-1138.

PEACH, C. (1974): 'Ethnic segregation in Sydney and intermarriage patterns', Australian Geographical Studies 12 (2): 219-229.

PEACH, C. (1980): 'Ethnic segregation and intermarriage', Annals of the Association of American Geographers 70 (3): 371-381.

PEACH, C. (2005): 'Social integration and social mobility: spatial segregation and intermarriage of the Caribbean population in Britain', in LOURY, G. C., MODOOD, T. and TELES, S. M. (eds): Ethnicity, Social Mobility and Public Policy: Comparing the US and UK. Cambridge University Press, Cambridge, pp. 178-203.

PLATT, L., SIMPSON, L. and AKINWALE, B. (2005): 'Stability and change in ethnic groups in England and Wales', Population Trends 121: 35-46.

PORTES, A. and ZHOU, M. (1993): 'The new second generation: segmented assimilation and its variants', Annals of the American Academy of Political and Social Sciences 530: 74-96.

PORTES, A. and RUMBAUT, R. G. (2001): Legacies: The Story of the Immigrant Second Generation. University of California Press, Berkeley, CA.

PRICE, P. L. (2010): 'At the crossroads: critical race theory and critical geographies of race', Progress in Human Geography 34 (2): 147-174.

QIAN, Z. and LICHTER, D. T. (2007): 'Social boundaries and marital assimilation: interpreting trends in racial and ethnic intermarriage', American Sociological Review 72 (1): 68-94.

ROSENFELD, M. J. (2002): 'Measures of assimilation in the marriage market: Mexican Americans 1970-1990', Journal of Marriage and Family 64 (1): 152-162.

SIGELMAN, L., BLEDSOE, T., WELCH, S. and COMBS, M. W. (1996): 'Making contact? Black-white social interaction in an urban setting', American Journal Sociology 101 (5): 1306-1332.

SIMPSON, L. and FINNEY, N. (2009): 'Spatial patterns of internal migration: evidence for ethnic groups in Britain', Population, Space and Place 15 (1): 37-56.

STILLWELL, J. and VAN HAM, M. (2010): 'Ethnicity and integration', in STILLWELL, J. and VAN HAM, M. (eds): Ethnicity and Integration. Understanding Population Trends and Processes 3, Springer, Heidelberg, pp. 1-25.

TOLSMA, J., LUBBERS, M. and COENDERS, M (2008): 'Ethnic competition and opposition to ethnic intermarriage in the Netherlands: a multi-level approach', European Sociological Review 24 (2): 215-230. 
VAN HAM, M. and FEIJTEN, P. M. (2008): 'Who wants to leave the neighbourhood? The effect of being different from the neighbourhood population on wishes to move', Environment and Planning A 40 (5): 1151-1170.

VAN HAM, M. and MANLEY, D. (2010): 'The effect of neighbourhood housing tenure mix on labour market outcomes: a longitudinal investigation of neighbourhood effects', Journal of Economic Geography 10 (2): 257-282.

VOAS, D. (2009): 'The maintenance e and transformation of ethnicity: evidence on mixed partnerships in Britain', Journal of Ethnic and Migration Studies 33 (9): 1497-1513.

WESSEL, T. (2009): 'Does diversity in urban space enhance intergroup contact and tolerance?' Geografiska Annaler: Series B, Human Geography 91 (1): 5-17.

WONG, D. W. S. (1999): 'A geographical analysis of multiethnic households in the United States', International Journal of Population Geography 5 (1): 31-48. 
Table 1: Ethnic definitions in the 1991 and 2001 censuses.

\begin{tabular}{|c|c|c|}
\hline Ethnic group & 1991 & 2001 \\
\hline White & White & $\begin{array}{l}\text { British } \\
\text { Irish } \\
\text { Other White }\end{array}$ \\
\hline Black & $\begin{array}{l}\text { Black-Caribbean } \\
\text { Black-African } \\
\text { Black Other } \\
\text { Black and White }\end{array}$ & $\begin{array}{l}\text { Black-Caribbean } \\
\text { Black-African } \\
\text { Other Black } \\
\text { White and Black- } \\
\text { Caribbean } \\
\text { White and Black-African }\end{array}$ \\
\hline South Asian & $\begin{array}{l}\text { Indian } \\
\text { Pakistani } \\
\text { Bangladeshi }\end{array}$ & $\begin{array}{l}\text { Indian } \\
\text { Pakistani } \\
\text { Bangladeshi }\end{array}$ \\
\hline Other Asian & $\begin{array}{l}\text { Chinese } \\
\text { Other Asian }\end{array}$ & $\begin{array}{l}\text { Chinese } \\
\text { Other Asian }\end{array}$ \\
\hline Other & $\begin{array}{l}\text { Other ethnic group: } \\
\text { non-mixed origin } \\
\text { Other ethnic group: } \\
\text { mixed origin }\end{array}$ & $\begin{array}{l}\text { White and Asian } \\
\text { Other mixed } \\
\text { Other ethnic group }\end{array}$ \\
\hline
\end{tabular}

Source: Office for National Statistics Longitudinal Study 
Table 2: Partnership status in 2001 by ethnic group for singles aged 6 and over in 1991.

\begin{tabular}{lrrrr}
\hline Ethnic group & \multicolumn{1}{l}{$\begin{array}{l}\text { Co-ethnic } \\
\text { union }\end{array}$} & \multicolumn{1}{l}{$\begin{array}{l}\text { Mixed-ethnic } \\
\text { union }\end{array}$} & Single & \multicolumn{1}{l}{ Total } \\
\hline Black & $231(9.5 \%)$ & $207(8.5 \%)$ & $1,984(81.9 \%)$ & $2,422(100 \%)$ \\
South Asian & $1,034(25.7 \%)$ & $120(3.0 \%)$ & $2,863(71.3 \%)$ & $4,017(100 \%)$ \\
Other Asian & $100(14.3 \%)$ & $70(10.0 \%)$ & $527(75.6 \%)$ & $697(100 \%)$ \\
\hline $\begin{array}{l}\text { Total for } \\
\text { minority } \\
\text { groups }\end{array}$ & $1,365(19.1 \%)$ & $397(5.6 \%)$ & $5,374(75.3 \%)$ & $7,136(100 \%)$ \\
\hline & 37,116 & & 85,005 & 122,781 \\
White & $(30.2 \%)$ & $660(0.5 \%)$ & $(69.2 \%)$ & $(100 \%)$
\end{tabular}

Source: Office for National Statistics Longitudinal Study, Authors' calculations 
Table 3: Characteristics of LS members who were single in 1991 (\%).

\begin{tabular}{|c|c|c|c|c|c|}
\hline Variable & Category & Black & $\begin{array}{l}\text { South } \\
\text { Asian }\end{array}$ & $\begin{array}{l}\text { Other } \\
\text { Asian }\end{array}$ & White \\
\hline \multirow[t]{2}{*}{ Gender } & Male & 43.8 & 49.4 & 51.4 & 48.8 \\
\hline & Female & 56.2 & 50.6 & 48.6 & 51.2 \\
\hline \multirow[t]{3}{*}{ Age 1991} & $6-14$ & 34.9 & 51.8 & 40.6 & 35.3 \\
\hline & $15-24$ & 47.2 & 40.7 & 44.8 & 41.3 \\
\hline & 25 and over & 17.9 & 7.4 & 14.6 & 23.5 \\
\hline \multirow[t]{2}{*}{$\begin{array}{l}\text { Country of } \\
\text { Birth }\end{array}$} & Born in UK & 74.7 & 67.4 & 54.8 & 97.1 \\
\hline & Born outside UK & 25.3 & 32.6 & 45.2 & 2.9 \\
\hline \multirow[t]{2}{*}{ Qualification* } & No degree & 93.0 & 92.4 & 82.8 & 91.1 \\
\hline & With Degree & 7.0 & 7.6 & 17.2 & 8.9 \\
\hline \multirow[t]{5}{*}{ Social Class* } & $\begin{array}{l}\text { Professional \& } \\
\text { managerial }\end{array}$ & 20.7 & 19.9 & 30.7 & 18.0 \\
\hline & Skilled non-manual & 21.7 & 13.8 & 18.5 & 21.3 \\
\hline & Skilled Manual & 14.7 & 19.4 & 20.1 & 18.9 \\
\hline & $\begin{array}{l}\text { Partly skilled \& } \\
\text { unskilled }\end{array}$ & 21.0 & 23.2 & 10.9 & 26.3 \\
\hline & Not Stated & 21.9 & 23.7 & 19.8 & 15.6 \\
\hline \multirow[t]{3}{*}{ Housing tenure } & Owned & 49.7 & 81.0 & 71.3 & 73.0 \\
\hline & Social renting & 44.1 & 13.9 & 17.9 & 21.1 \\
\hline & Private renting & 6.2 & 5.1 & 10.8 & 5.9 \\
\hline \multirow[t]{5}{*}{ Region } & North East/Yorkshire & 7.6 & 14.0 & 6.9 & 16.7 \\
\hline & North West/Wales & 8.5 & 7.6 & 8.6 & 13.7 \\
\hline & Midlands & 11.6 & 13.3 & 21.8 & 25.4 \\
\hline & South & 22.8 & 32.3 & 17.8 & 32.8 \\
\hline & London & 49.6 & 32.9 & 44.8 & 11.3 \\
\hline
\end{tabular}

* Head of household data used for those under 21 in full-time education 
Source: Office for National Statistics Longitudinal Study, Authors' calculations 
...Table 4. Odds ratios of forming a mixed-ethnic union compared to forming a co-ethnic union between 1991 and 2001 by ethnic group; results from multinomial logistic regression.

\begin{tabular}{|c|c|c|c|c|c|c|c|c|}
\hline & \multicolumn{2}{|c|}{ Black $(\mathrm{N}=438)$} & \multicolumn{2}{|c|}{ South Asian $(\mathrm{N}=1154)$} & \multicolumn{2}{|c|}{ Other Asian $(\mathrm{N}=170)$} & \multicolumn{2}{|c|}{ White $(\mathrm{N}=37,776)$} \\
\hline Variable & $\begin{array}{l}\text { Odds } \\
\text { ratio }\end{array}$ & $95 \% \mathrm{CI}$ & $\begin{array}{l}\text { Odds } \\
\text { ratio }\end{array}$ & $95 \% \mathrm{CI}$ & $\begin{array}{l}\text { Odds } \\
\text { ratio }\end{array}$ & $95 \% \mathrm{CI}$ & $\begin{array}{l}\text { Odds } \\
\text { ratio }\end{array}$ & $95 \% \mathrm{CI}$ \\
\hline \multicolumn{9}{|l|}{ Gender } \\
\hline Male & 1.00 & & & & & & & \\
\hline Female & 1.22 & $(0.82-1.81)$ & 0.96 & $(0.66-1.39)$ & 2.18 & $(1.13-4.18)^{* *}$ & 1.11 & $(0.94-1.30)$ \\
\hline \multicolumn{9}{|l|}{ Age 1991} \\
\hline $6-14$ & 2.16 & $(1.02-4.61)^{* *}$ & 0.43 & $(0.22-0.84)^{* *}$ & 1.79 & $(0.58-5.55)$ & 1.45 & $\begin{array}{l}(1.17- \\
1.80)^{* * *}\end{array}$ \\
\hline $15-24$ & 1.00 & & 1.00 & & 1.00 & & 1.00 & \\
\hline 25 and over & 0.92 & $(0.59-1.43)$ & 3.83 & $\begin{array}{l}(2.33- \\
6.29)^{* * *}\end{array}$ & 1.17 & $(0.52-2.61)$ & 1.14 & $(0.95-1.36)$ \\
\hline \multicolumn{9}{|l|}{ Country of birth } \\
\hline born in UK & 1.00 & & 1.00 & & 1.00 & & 1.00 & \\
\hline born outside UK & 0.28 & $\begin{array}{l}(0.16- \\
0.50)^{* * *}\end{array}$ & 0.46 & $\begin{array}{l}(0.29- \\
0.72)^{* * *}\end{array}$ & 0.42 & $(0.18-0.95)^{* *}$ & 1.17 & $(0.79-1.75)$ \\
\hline \multicolumn{9}{|l|}{ Qualification } \\
\hline no degree & 1.00 & & 1.00 & & 1.00 & & 1.00 & \\
\hline degree and above & 0.59 & $(0.28-1.25)$ & 0.68 & $(0.37-1.25)$ & 1.05 & $(0.41-2.66)$ & 1.42 & $\begin{array}{l}(1.10- \\
1.83)^{* * *}\end{array}$ \\
\hline
\end{tabular}


Professional \& managerial

Skilled non-manual

Skilled Manual

Partly skilled \& unskilled

Not Stated

Housing tenure

owner occupied

Social renting

Private renting

Region

North East/Yorkshire

North West/Wales

Midlands

South

London

Co-ethnic concentration

$\%$ co-ethnic group,

district

$0.91(0.85-0.99)^{*}$

$(0.87-$

$\%$ co-ethnic group, ward

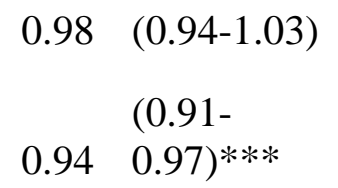

1.00

1.00

1.00

(1.03-

$(1.54-$

$\begin{array}{lllllllll}1.16 & (0.61-2.18) & 3.02 & 5.90)^{* * *} & 2.41 & (0.73-7.95) & 0.94 & (0.73-1.22) \\ 0.72 & (0.40-1.30) & 2.30 & (1.19-4.46)^{* *} & 1.07 & (0.32-3.53) & 0.98 & (0.76-1.25) \\ & & & & & & (1.29- \\ 0.87 & (0.48-1.60) & 1.87 & (0.91-3.82)^{*} & 4.77 & 17.69)^{* *} & 1.11 & (0.87-1.42) \\ 1.00 & & 1.00 & & 1.00 & & 1.00 & \\ 0.80 & (0.42-1.53) & 1.07 & (0.53-2.18) & 1.24 & (0.34-4.51) & 1.20 & (0.86-1.68)\end{array}$

1.00

1.00

1.00

$1.32 \quad(0.85-2.04) \quad 0.91 \quad(0.49-1.66)$

$1.38 \quad(0.52-3.63)$

$1.03 \quad(0.83-1.27)$

$1.32(0.63-2.76)$

$0.70 \quad(0.26-1.87)$

$1.32(1.02-1.70) * *$

$\begin{array}{lllllllll}0.67 & (0.25-1.80) & 0.61 & (0.21-1.81) & 5.72 & 31.69)^{* *} & 1.13 & (0.82-1.54) \\ 1.20 & (0.46-3.13) & 1.56 & (0.73-3.34) & 2.32 & (0.56-9.68) & 1.25 & (0.95-1.64) \\ 0.89 & (0.38-2.08) & 1.31 & (0.65-2.64) & 1.22 & (0.29-5.02) & 1.19 & (0.91-1.55) \\ & & & & & & & & (1.18- \\ 0.61 & (0.24-1.53) & 1.38 & (0.67-2.83) & 1.46 & (0.21-10.05) & 1.66 & 2.32)^{* * *}\end{array}$

$0.61 \quad(0.24-1.53) \quad 1.38 \quad(0.67-2.83)$

$1.46 \quad(0.21-10.05)$

1.00

$.662 .32)^{* * *}$

$\begin{array}{llll}1.07 & (0.51-2.22) & 1.05 & (0.99-1.11)^{*} \\ & (0.25- & & \\ 0.45 & 0.80)^{* * *} & 1.05 & (1.00-1.1)^{*}\end{array}$


$\%$ co-ethnic group,

(1.00-

district*ward

$1.011 .01)^{* * *}$

$1.00(1.00-1.00)^{* *}$

$1.18(1.00-1.39)^{*}$

$1.00(1.00-1.00) * *$

$* \mathrm{p}<0.10 * * \mathrm{p}<0.05 * * * \mathrm{p}<0.01 ; \mathrm{N}$ refers to the number in unions by 2001.

Source: Office for National Statistics Longitudinal Study, Authors' calculations 
...Figure 1. Probability of forming a partnership with a White person among Black singles by 1991

district and ward concentration.

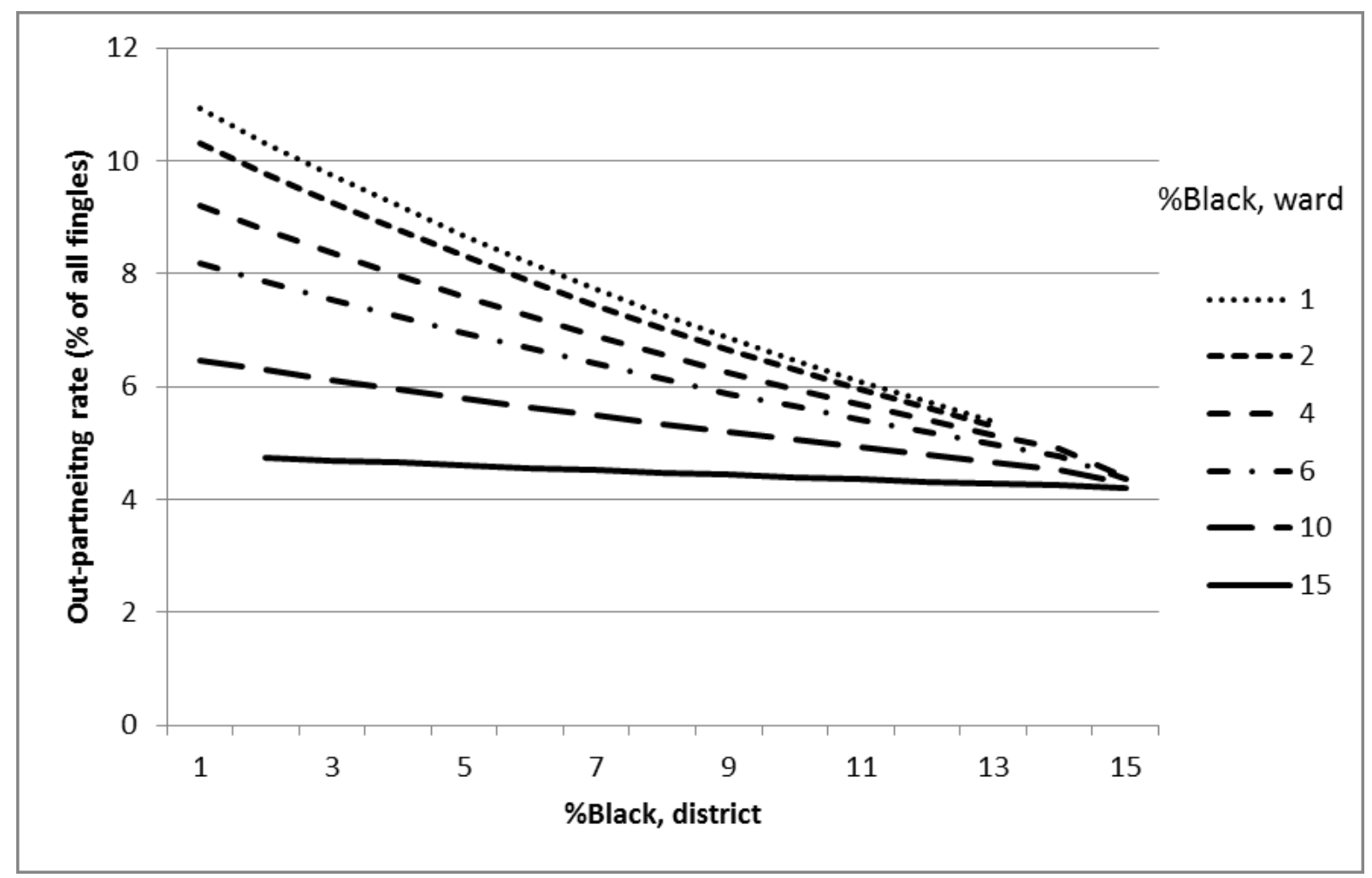

Source: Office for National Statistics Longitudinal Study, authors' calculations. 
Figure 2. Probability of forming a partnership with a White person among South Asian singles by

1991 district and ward concentration.

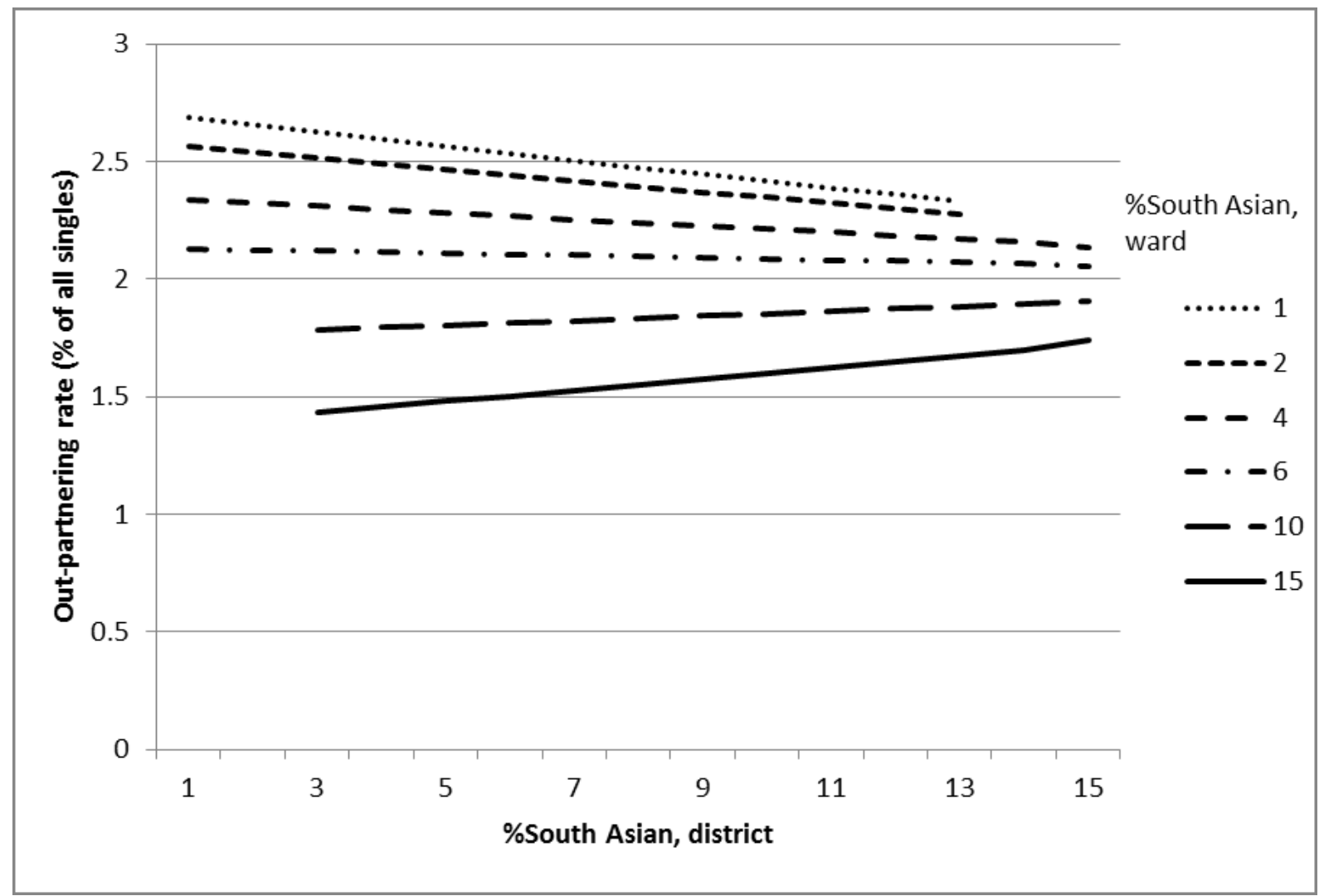

Source: Office for National Statistics Longitudinal Study, authors' calculations. 
Figure 3. Probability of forming a partnership with a White person among Other Asian singles by

1991 district and ward concentration.

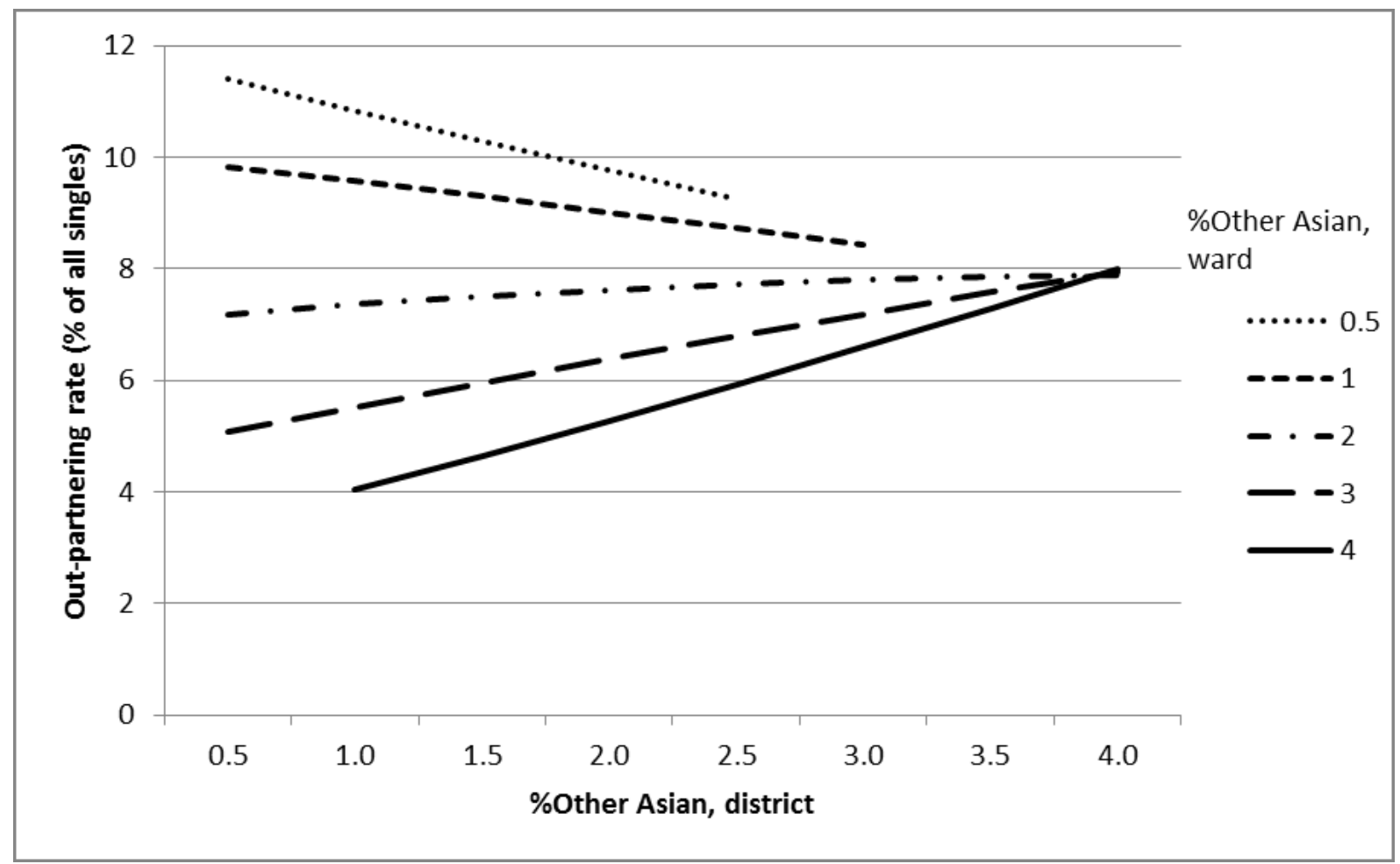

Source: Office for National Statistics Longitudinal Study, authors' calculations. 
Figure 4. Probability of forming a partnership with a non-White person among White singles by

1991 district and ward concentration.

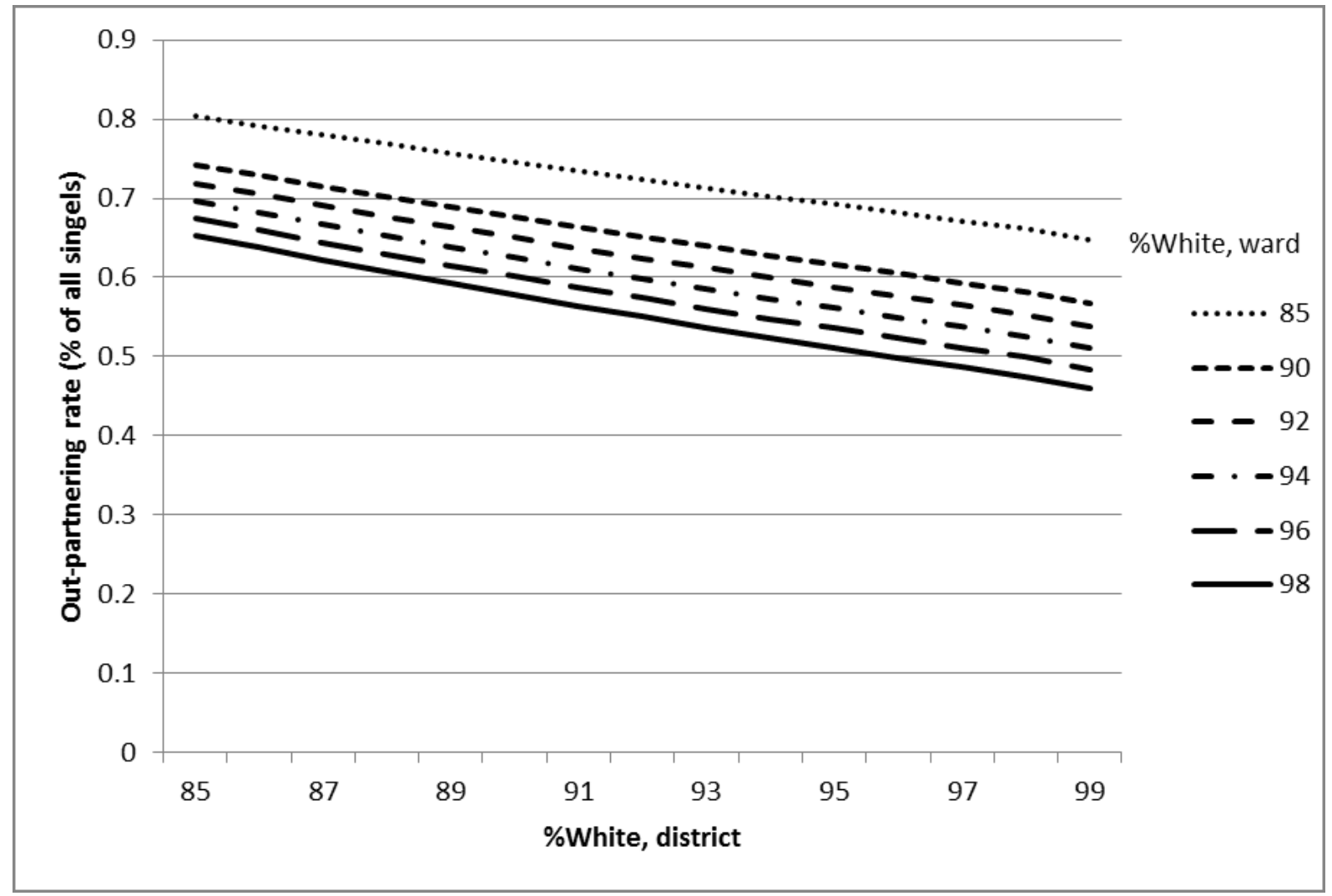

Source: Office for National Statistics Longitudinal Study, authors' calculations. 